\title{
VACCINE CONFIDENCE IN KHYBER PAKHTUNKHWA IN LIGHT OF RECENT UPSURGE IN POLIO CASES: A VIEW BY PUBLIC HEALTH ASSOCIATION- KHYBER PAKHTUNKHWA, PAKISTAN

\author{
Zawar Ali ${ }^{\otimes I}$, Saima Abid², Imtiaz Ali Shah, \\ Maqsood $\mathrm{Ali}^{4}$, Abu Zar Taizai ${ }^{5}$
}

Vaccine hesitancy as defined by World Health Organization (WHO) refers to "delay in acceptance or refusal of vaccines despite availability of vaccination services. Vaccine hesitancy is complex and context specific, varying across time, place and vaccines. It is influenced by factors such as complacency, convenience and confidence." Vaccine hesitancy is a multidimensional complex phenomenon with many determinants. ${ }^{2,3}$ It is usually seen amongst specific subgroups of population within a country and have certain context. Vaccine hesitancy is not always related to one specific vaccine. Sometimes it is against immunization in general. It is important to understand who is hesitant towards vaccines or the immunization program and why. ${ }^{4}$ Many models are available to understand and help elucidate this phenomenon. WHO has adopted "the $3 \mathrm{C}$ model" as it is readily understandable and has incorporated the themes in its definition as well i.e. complacency, convenience and confidence. ${ }^{5}$ Complacency and convenience are important determinants of vaccine hesitancy, in this write up we will keep ourselves limited to discussion on vaccine confidence. Vaccine confidence implies "trust in the vaccine (the product), trust in the vaccinator or other health professional (the provider), and trust in those who make the decisions about vaccine provision (the policy-maker)." It is the trust of the public not only on the vaccine itself but also the healthcare workers and the government that leads to vaccine confidence.

In the context of polio eradication in Pakistan, the debate on vaccine confidence gains more importance, especially in Khyber Pakhtunkhwa (KP) province. The province has had more cases per population even by national standards. With more than two-thirds of polio cases from Pakistan, reported from Khyber Pakhtunkhwa. ${ }^{7}$ The routine EPI coverage in KP is below national standards as well. The lack of vaccine confidence has been evident in our province for a few years. In April 2019 , in response to rumours about children having side effects from polio drops, a lynch mob attacked a health facility in Peshawar and the polio campaign had to be abandoned. ${ }^{8}$ What surprised members of KP Public Health Association (PHA) was the intensity of the reaction than the reaction itself. This was a strong expression of lack of trust not just in the vaccine, but the health apparatus that delivers it and the institutions that make vaccination policy.

The goal of polio eradication is difficult to achieve under these conditions of vaccine hesitancy. To increase public confidence we need to identify factors influencing acceptance of vaccination in our specific cultural context. It is evident that the context in KP is different from other areas of the country. Myths and misconceptions regarding the vaccine
THIS ARTICLE MAY BE CITED AS: Ali Z, Abid S, Shah IA, Ali M, Taizai AZ. Vaccine confidence in Khyber Pakhtunkhwa in light of recent upsurge in polio cases: A view by Public Health Association- Khyber Pakhtunkhwa, Pakistan. Khyber Med Univ J 2019; I I (2): I07-8. DOI: 10.35845/kmuj.2019.193।8
I. Consultant Volcanologist, Orbit Health, Islamabad, Pakistan

Email区 : zawar.ali@orbithealth.com.pk Contact \#: +92-336-3391579

2. Honorary President Public Health Association Khyber Pakhtunkhwa, Pakistan

3. Focal Person for Polio Eradication, Khyber Pakhtunkhwa, Pakistan

4. Director Coordination M\&E and Linkages, Provincial Health Services Academy \& Allied Institutions, Peshawar, Pakistan

5. District Officer for Prevention of communicable \& non-communicable diseases, Nowshera, Pakistan

need to be addressed and it is encouraging that the government is working on this. To build trust in the apparatus that provides these vaccines, it is important to look at the health sector as a whole and not just polio vaccinators. Increasing vaccine literacy amongst health care providers will go a long way in increasing vaccine confidence. Polio eradication needs to be the goal of all healthcare providers in the province. Healthcare providers are the most trusted influencers of decisions regarding vaccination.' The government should educate doctors on vaccines and their recommendations and make them a part of the process. Vaccinology education for doctors is an important part of this process in many countries in the world and even regional countries like India. ${ }^{10-13}$

Finally, to establish trust in the policymakers, there needs to be transparency and predictability. Good communication is an important prerequisite for this. The public needs to be taken into confidence regarding vaccination policies and any change in policy needs to be communicated in advance. If the policymaking process seems opaque to the public, it will be difficult to establish trust. Public health bodies like PHA KP can play an important role as intermediaries in educating public about vaccination policies.

Disclaimer: This viewpoint was submitted by authors on behalf of Public Health Association, Khyber Pakhtunkhwa, Pakistan.

\section{REFERENCES}

I. The Strategic Advisory Group of 
Experts (SAGE). (20I4). Report of the SAGE working group on vaccine hesitancy. SAGE REPORT. [Cited on: May 03, 2019]. Available from URL https://www.who.int/immunization/s age/meetings/20I4/october/SAGE_w orking_group_revised_report_vaccin e_hesitancy.pdf?ua $=$ I

2. Cooper LZ, Larson HJ, Katz SL. Protecting public trust in immunization. Pediatrics 2008 Jul I;I22(I):I49-53. DOI: I0. I542/peds. 2008-0987

3. Larson HJ, Cooper LZ, Eskola J, Katz SL, Ratzan S. Addressing the vaccine confidence gap. Lancet 201I Aug $6 ; 378(9790): 526-35$. DOI: 10.1016/S0I40-6736(II)60678-8.

4. Larson HJ, Jarrett C, Schulz WS, Chaudhuri M, Zhou Y, Dube E, et al. Measuring vaccine hesitancy: The development of a survey tool. Vaccine 2015 Aug 14:33(34):4165-75. DOI: 10.1016/j.vaccine.20I5.04.037.

5. MacDonald NEI; SAGE Working Group on Vaccine Hesitancy. Vaccine hesitancy: Definition, scope and determinants. Vaccine 2015 Aug |4;33(34):4|6I-4. DOI:I0.1016/ j.vaccine.20I5.04.036

6. Larson HJ, Schulz WS, Tucker JD, Smith DM. Measuring vaccine confidence: introducing a global vaccine confidence index. PLoS Curr 2015 Feb 25;7. pii:ecurrents. outbreaks.ce0f6I $77 \mathrm{bc} 97332602 \mathrm{a} 8 \mathrm{e} 3$ fe7d7f7cc4. DOI: 10.1371/currents. outbreaks.ce0f6I 77bc97332602a8e3 fe7d7f7cc4.

7. Endpolio Pakistan. Polio cases district wise | polio cases in Pakistan. [Cited on: May 03, 2019]. Available from URL: http://www.endpolio.com.pk/ polioin-pakistan/polio-cases-districtwise-2019

8. The Express Tribune. Health unit set on fire in protest sparked by polio vaccine in Peshawar. [Cited on: May 03, 2019]. Available from URL: https://tribune.com.pk/story/195638 I / - polio-vaccination-drivepeshawar-triggers-controversy/

9. Paterson P, Meurice F, Stanberry LR, Glismann S, Rosenthal SL, Larson HJ.
Vaccine hesitancy and healthcare providers. Vaccine. $2016 \mathrm{Dec}$ 20;34(52):6700-06. DOI:10.1016/ j.vaccine.2016.10.042

10. Duclos P, Martinez L, MacDonald N, Asturias E, Nohynek H, Lambert PH, et al. Global vaccinology training: Report from an ADVAC workshop. Vaccine 20 I 9 May I6;37(22):287 I-8 I. DOI: 10.1016/j.vaccine.2019.02.062.

I I. Gerke C, Phalipon A, Tangy F. Bringing vaccinology to the world. Hum Vaccin Immunother 20I8; I 4(9):2105-6. DOI: $10.1080 / 2|6455| 5.20 \mid 8$. 1490379.

12. Lambert PH, Podda A. Education in Vaccinology: An Important Tool for Strengthening Global Health. Front Immunol 2018 May 24;9: I I34. DOI: I $0.3389 / \mathrm{fimmu} .2018 .01 \mid 34$ eCollection 2018.

13. O'Brien J. Advancing vaccinology in India. Expert Rev Vaccines 2012 Jan;II (I):27-9. DOI: I0.I586/erv. II.169
CONFLICT OF INTEREST

Authors declared no conflict of interest GRANT SUPPORT AND FINANCIAL DISCLOSURE NIL

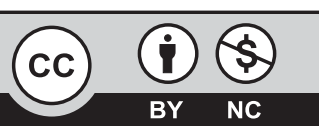

This is an Open Access article distributed under the terms of the Creative Commons Attribution-Non Commercial 2.0 Generic License.
KMUJ web address: www.kmuj.kmu.edu.pk Email address: kmuj@kmu.edu.pk 